\title{
Bergson e a Natureza Temporal da Vida Psíquica
}

\author{
Regina Rossetti ${ }^{1}$ \\ Universidade de São Paulo ${ }^{2}$
}

\begin{abstract}
Resumo
Para Bergson, a vida interior é de natureza temporal e não espacial. Na psique, a multiplicidade qualitativa dos estados psicológicos se modifica o tempo todo numa sucessão contínua e solidária; se algo parece solidificar-se e fragmentar-se é porque se representa, ilusoriamente, a consciência como se existisse num tempo homogêneo e espacial. Na raiz do problema está a confusão que se faz entre tempo e espaço quando não se percebe que os estados psicológicos e toda vida psíquica são de natureza exclusivamente temporal. A partir dessa confusão, tem-se a representação de um eu superficial e de uma multiplicidade quantitativa dos estados psicológicos como se fossem de natureza física, como o fez a psicofísica, porque se concebe a vida psíquica existindo num ilusório tempo espacial.

Palavras-chave: Bergson; tempo; psicológico; espaço.
\end{abstract}

\section{Bergson and the Temporal Nature of Psychological Life}

\begin{abstract}
For Bergson, interior life is temporal and not spatial in nature. In the "psyché", the qualitative multiplicity of psychological states modifies itself all the time in a continuous and solidary succession; if something seems to solidify and to fragment it is because conscience is represented, illusorily, as if it existed in a homogeneous and spatial time. In the root of the problem lies the confusion that is done between time and space when it is not noticed that the psychological states and all psychic life are exclusively of a temporal nature. Starting from this confusion, one has the representation of oneself and a quantitative multiplicity of psychological states as if they were of a physical nature, as psychophysics did, because psychic life is conceived as existing in an illusory spatial time.

Keywords: Bergson; time; psychological space.
\end{abstract}

O filósofo Henri Bergson é um crítico dos pressupostos filosóficos da ciência de sua época, particularmente, da psicologia e da biologia. O período que compreende o final do século XIX e o começo do século XX é marcado pelo positivismo e pelo cientificismo; as ciências particulares deveriam seguir o paradigma das ciências positivas - cujo modelo era a física - e assim trabalhar com dados empíricos e mensuráveis submetidos à lei de causalidade. Nessa atmosfera científica, desenvolveram-se pesquisas que buscavam determinar um paralelismo rigoroso entre a vida psíquica e o cérebro; este fato contribuiu para que a psicologia tivesse seu ramo psicofísico reforçado: a psicologia passou a buscar no físico a explicação do psíquico e a propor a quantificação dos fenômenos psicológicos a partir de suas pretensas causas físicas. Neste contexto, Bergson se coloca como um crítico da psicofísica e seu determinismo psicológico, mostrando que o campo de investigação da psicologia, dada a

\footnotetext{
${ }^{1}$ Endereço para correspondência: Rua José Colleoni, 127/13, Santo André, 09181-590, SP. Fax/Fone: (11) 44278512.E-mail: epitofilos@uol.com.br

${ }^{2}$ Este artigo é resultado de pesquisa de pós-doutorado financiada pela FAPESP.
}

própria natureza de seu objeto, estende-se para além do meramente material. Segundo o filósofo, a psicofísica, que entendia os fatos da consciência como se fossem de natureza física, reduziu o mental ao cerebral e pensou poder medir os fenômenos psíquicos da mesma maneira como era possível medir os fenômenos físicos. Assim procederam porque não perceberam a distinção fundamental entre tempo e espaço - e, conseqüentemente, entre interioridade e exterioridade - e tentaram fazer dos estados internos da consciência uma multiplicidade quantitativa, isto é, uma justaposição numérica e espacial dos estados psicológicos, marcados pela exterioridade recíproca de seus elementos, como veremos. Não se deram conta de que a realidade psicológica é pura duração, isto é, uma sucessão indistinta da multiplicidade qualitativa dos estados da consciência que se interpenetram em constante e continua mudança. Ao confundirem o tempo com o espaço atribuíram extensão àquilo que somente possui intensidade pura e, assim, trataram a realidade psíquica como se fosse espacial, exterior e extensa. Já em um de seus primeiros estudos, Ensaio sobre os Dados Imediatos da Consciência (1889/1988), Bergson trata desses pressupostos filosóficos da psicologia de sua época, criticando seu determinismo psicofísico. 


\section{O Eu Profundo e o Eu Superficial}

Para entender a natureza da vida psíquica, Bergson distingue dois eus existindo no psiquismo. Segundo o filósofo: "Haveria, pois, dois eus diferentes, sendo um como que a projeção do outro, a sua representação espacial, por assim dizer social" (Bergson, 1889/1988, p. 159); este é um eu superficial. Por outro lado, haveria também, na duração de nossa vida interior, o eu profundo, que experimentamos através de "nossos estados internos como seres vivos, incessantemente em vias de formação, como estados refratários à medida que se penetram reciprocamente e cuja sucessão na duração nada tem de comum com uma justaposição no espaço homogêneo" (Bergson, p. 159).

Trata-se de dois momentos na totalidade da vida psíquica, que nem por isto perde sua unidade: um mais superficial e outro mais profundo. Esse aspecto do eu total que aparentemente não dura, porque adere à realidade exterior, o eu superficial, é a apenas a crosta rígida da psique que encobre o verdadeiro eu. "Pode-se deduzir que a relação do eu profundo e do eu superficial não será de exclusão absoluta, mas de recobertura" (Trotignon,1967, p.103). Se escavarmos por baixo dessa superfície de contato com as coisas exteriores, penetraremos nas profundezas da consciência e chegaremos ao eu profundo, vivendo na pura duração:

"É, por sob estes cristais bem recortados e este congelamento superficial, uma continuidade que se escoa de maneira diferente de tudo o que já vi escoar-se. É uma sucessão de estados em que cada um anuncia aquele que o segue e contém o que o precedeu" (Bergson, 1903/1984, p. 16).

Da mesma maneira, mas indo à direção oposta, Bergson esclarece o processo pelo qual o eu profundo superficializa-se:

"Pouco a pouco, estes estados (profundos) transformamse em objetos ou em coisas; não se separam apenas um do outro, mas também de nós. Então só os percepcionamos no meio homogêneo em que condensamos a sua imagem e através da palavra, que lhes empresta a sua banal coloração. Assim se forma um segundo eu que esconde o primeiro, num eu cuja existência tem momentos distintos, cujos estados se separam um dos outros e se exprimem sem dificuldade, por meio de palavras" (Bergson, 1889/1988, p. 96).

$\mathrm{O}$ eu profundo sofre a influência do eu superficial que caminha até as profundezas da consciência dominando nossas sensações, sentimentos e idéias que, então, desprendem-se uns dos outros e justapõem-se numa duração homogênea. E isto ocorre a maior parte do tempo em que vivemos exteriormente a nós mesmos.

Por um esforço da inteligência e movidos pela necessidade de sobrevivência, representamo-nos existindo mais no tempo espacializado do que no tempo real que dura, o que torna difícil uma existência verdadeiramente livre, vivida pelo eu profundo. O papel da inteligência é fundamental para compreendermos a natureza desse eu superficial. Segundo Bérgson, podemos "distinguir duas maneiras profundamente diferentes de conhecer uma coisa. A primeira implica que rodeemos a coisa; a segunda, que entremos nela" (Bergson, 1903/1984, p.13). A primeira é a inteligência; a segunda, a intuição; uma é conhecimento exterior; a outra, conhecimento interior. Uma surge moldada à matéria e é por ela limitada e situada; a outra é conhecimento do espírito, não tem fronteiras e pode ver a totalidade. A primeira conhece somente imobilidade; a outra é a única que pode alcançar a essência movente da realidade. Por ser conhecimento exterior, a primeira é conceitual por natureza; a segunda, pela sua interioridade, é inexprimível. Assim, a inteligência, como conhecimento exterior, é a maneira própria de conhecer que objetiva nossa ação no mundo exterior. A inteligência é sempre operacional para Bergson, e o eu que está em contato com o mundo e assim pode relacionar-se socialmente e manipular os objetos exteriores é o eu superficial, então, a inteligência é seu modo próprio de conhecer.

Em suma, numa direção da vida psíquica temos o eu superficial que toca o mundo exterior pela superfície, está em contato direto com as causas externas das sensações conservando delas algo de sua exterioridade e, ao olhar para si, divide a vida psíquica em partes distintas à imagem das coisas exteriores com as quais se relaciona. Este eu rígido cujos estados são bem definidos, se presta muito melhor às exigências da vida social e prática, pois tem o formato das coisas distintas e definidas com as quais tem que lidar para sobreviver. Em outra direção, temos o eu profundo, assim descrito por Bergson: "o eu interior, o que sente e se apaixona, o que delibera e decide, é uma força cujos estados e modificações se penetram intimamente" (Bergson, 1889/1988, p. 88). O eu profundo move-se livremente, longe da estabilidade e imobilidade da exterioridade material. Nele estão os sentimentos mais íntimos, as paixões mais profundas, os pensamentos mais próprios, a vontade mais livre, porque nele os estados mais profundos duram sem a influência estabilizadora do exterior; nele as sensações, percepções e emoções se organizam de forma autêntica, viva e original.

\section{A Natureza Qualitativa dos Estados Psicológicos}

Aprofundado nosso estudo, vemos que a consciência no eu profundo é constituída por uma multiplicidade qualitativa de estados psicológicos que se sucedem, interpenetrando-se em contínua mudança. Esta 
multiplicidade dos estados psíquicos é qualitativa e não deve ser confundida com uma multiplicidade quantitativa, típica do eu superficial. Portanto, é necessário distinguir dois tipos de multiplicidade: uma quantitativa, outra qualitativa. A primeira, objetiva e exterior, refere-se aos objetos extensos; a segunda, subjetiva e interior, refere-se aos fatos da consciência.

Antes devemos entender que consciência para Bergson não é a consciência intencional da fenomenologia, ou seja, consciência de alguma coisa, isto é, a consciência que visa o objeto. Para Bergson, "a consciência é o traço de união entre o que foi e o que será, uma ponte entre o passado e o futuro" (Bergson, 1903/1984, p.71). Assim, consciência é memória do passado e antecipação do futuro iminente, unidas numa continuidade incorruptível garantida pela duração que é a própria essência da consciência. Consciência é o próprio movimento de sucessão de seus estados, em interpenetração recíproca; a essa continuidade de movimentos Bergson (1889/1988, p.72) chama de duração pura. Quanto a sua origem, a consciência psicológica é o resultado da evolução da vida e do esforço do élan vital em introduzir na matéria uma corrente de consciência que fizesse surgir à vida. Na Evolução Criadora (1907/1964), Bergson descreve o movimento de evolução da vida desde seu impulso original de vida, o élan vital, até o surgimento do ser humano e, com ele, da consciência psicológica; através da consciência psicológica ainda atravessa a energia do élan vital que lhe garante as mesmas qualidades do movimento que a criou, dessa maneira, também, ela é criadora (artística e eticamente), una em seu movimento contínuo e múltipla em virtualidades.

Tratemos, agora, da primeira das multiplicidades referidas: a multiplicidade quantitativa ou multiplicidade numérica. Bergson (1889/1988, p. 57) chega à definição de multiplicidade quantitativa a partir de uma exaustiva análise da idéia de número. O número é construído da seguinte forma: primeiro as unidades a serem contadas devem ser consideradas idênticas entre si, distintas somente pelo lugar que ocupam no espaço; para tanto, devem ser retiradas todas suas qualidades, restando somente a extensão. Depois, para formar um número, estes objetos extensos e idênticos devem ser separados uns dos outros e justapostos num meio vazio e homogêneo - o espaço. Tem-se, assim, o número: uma coleção de unidades idênticas. Porém, aqui se torna necessário a intervenção do espírito: para formarem uma multiplicidade numérica, é necessário acrescentar novas unidades às já existentes, que se unificarão através da soma. Tal síntese das unidades através da soma é um ato do espírito, que possibilita ao número tornar-se uno e, portanto indivisível, todavia, esta indivisibilidade é

Psicologia: Reflexão e Crítica, 2001, 14(3), pp. 617-623 provisória porque a matéria com a qual o espírito constrói o número é o espaço e o espaço é sempre divisível. $\mathrm{O}$ processo pelo qual forma-se uma multiplicidade numérica dá-se pela soma de unidades justapostas no espaço e, por isso, percepcionadas simultaneamente. É a simultaneidade que destaca o caráter espacial, e não temporal, do número; isto porque, para que possamos contar os objetos extensos é necessário conservá-los e representá-los simultaneamente, o que seria impossível de ocorrer no tempo porque um instante não pode ser conservado para ser acrescentado a outro, logo, ela somente pode ocorrer no espaço. Podemos concluir que a idéia de espaço é aqui essencial, é a própria matéria com que o espírito constrói o número, que se torna assim, expressão do espaço. O objetivo de Bergson, ao formular a gênese do número, é enfatizar que todo número é espacial na origem, para então demonstrar a identidade da multiplicidade numérica com o espaço e sua conseqüente inadequação para definir os estados psicológicos que são de natureza temporal e qualitativa.

A multiplicidade numérica é clara para objetos exteriores, mas e quando se tratar da realidade interior? É inadequada. O erro do senso comum, elevado ao grau de ciência pela psicofisiologia, é tentar aplicar o princípio da multiplicidade numérica aos estados internos. O senso comum perguntaria: se os estados se sucedem na consciência por que não podemos então contá-los? Por vezes não dizemos: agora estou triste, depois indiferente, esperançoso e por fim radiante de alegria? Então é só contar... foram quatro estados diferentes que se sucederam. Raciocinam assim porque estão habituados a pensar que os fatos psíquicos à semelhança das coisas extensas formam uma multiplicidade numérica. Mas os estados da alma não estão no espaço, não possuem extensão, portanto, não podem ser justapostos nem percepcionados simultaneamente. Para estados internos é necessário que exista uma multiplicidade qualitativa.

Bergson, segundo Deleuze (1989, p. 29), chega à noção de multiplicidade qualitativa não somente por oposição à multiplicidade numérica, mas a partir da distinção entre sujeito e objeto. O objeto é aquele que pode ser dividido infinitas vezes, sem se desnaturar, conseqüentemente, um objeto ao dividir-se somente muda de grandeza, não muda de natureza. Este objeto será chamado, então, de multiplicidade numérica, porque segue o modelo do número que se divide sem mudar de natureza. Mesmo que estas divisões não cheguem a se realizar, mas somente sejam pensadas como possíveis, o aspecto total do objeto não muda, pois somente o seu grau varia. Por outro lado, podemos pensar um tipo de "divisão" da duração psicológica ocorrendo no sujeito, num sentido metafórico 
e não espacial de divisão. A vida psíquica, apesar de contínua, é múltipla em seus aspectos, portanto, e de certa forma, divide-se para formar uma multiplicidade. Entretanto, esta divisão é muito especial porque a duração ao dividir-se muda de natureza; se não mudasse permaneceria homogênea e seria, então, uma multiplicidade numérica. A verdadeira duração é heterogênea e a cada divisão podemos no momento considerá-la como indivisível. Nesta divisão, que na realidade é uma mudança essencial, surge "o outro" sem que com isto venham a existir "muitos" no sentido numérico, porque os "muitos" estados fundem-se num só e cada novo estado de consciência toma conta da alma inteira, resultando num mesmo e único estado que dura. Assim, a multiplicidade qualitativa consegue conciliar características aparentemente divergentes da duração psicológica: a heterogeneidade e a continuidade.

Bergson, (1889/1988, p. 63) ao revelar a noção de multiplicidade qualitativa, pôde respeitar a verdadeira natureza dos estados internos. Os estados psicológicos são qualidade pura, não tem nada a ver com quantidades; é exatamente esta sua natureza qualitativa que os impede de formarem uma multiplicidade numérica. Somente podemos empregar termos que designam quantidade quando nos referimos às coisas que ocupam lugar no espaço e podem justapor-se a fim de serem comparadas para serem medidas; essa comparação entre coisas semelhantes é o que permite sua quantificação. Contudo, não faz sentido buscar uma relação numérica entre qualidades, isto porque elas nunca são idênticas. Então, um estado interno, sendo qualitativo, nunca é igual a outro, sendo assim, não pode ser sobreposto e comparado, no intuito de buscar semelhanças quantitativas e de estabelecer graus de diferenciação, visando-se a construir uma multiplicidade numérica que se mostra, assim, inteiramente inadequada para representar a realidade interior.

Para estarmos a salvo de tais confusões devemos separar duas multiplicidades que são absolutamente distintas. Quando o meio é o espaço temos uma multiplicidade quantitativa; quando o meio é o tempo temos uma multiplicidade qualitativa. A primeira referese às coisas extensas e exteriores; a segunda refere-se aos estados intensivos e internos. Essa distinção entre multiplicidade quantitativa e multiplicidade qualitativa é assim resumida por Bergson:

"Considerados em si mesmos, os estados da consciência profundos não têm nenhuma relação com a quantidade, são qualidade pura; misturam-se de tal maneira que não se pode dizer se são um ou vários, nem sequer examiná-los sob este ponto de vista sem logo os desnaturar. A duração que assim criam é uma duração cujos momentos não constituem uma multiplicidade numérica" (Bergson, 1889/1988, p. 95).
Trata-se de uma multiplicidade de qualidades, porque os fatos da consciência são qualidade pura, penetram-se reciprocamente quando percepcionados de forma imediata. Todavia, quando representados simbolicamente no espaço tornam-se unidades homogêneas e exteriores umas às outras ocupando lugar no espaço. Tornam-se rígidas e impenetráveis formando uma multiplicidade distinta semelhante ao número e somente sob estas condições é que imaginamos contá-los, quando os projetamos no espaço. E este foi precisamente o engano de uma psicologia não atenta à constituição qualitativa dos estados psicológicos: não perceber que existem dois tipos distintos de multiplicidade, uma qualitativa e outra quantitativa.

Em suma, a multiplicidade quantitativa tem por condição o espaço, é nítida, precisa, sua função é separar e distinguir a realidade sempre indistinta e fluida, dandolhe limites e definindo-a na exterioridade. Tal multiplicidade diz respeito aos objetos externos, extensos e materiais, que podemos ver e tocar porque estão no espaço. Estes objetos, por serem exteriores uns aos outros, estão justapostos de forma definida e ordenada formando um conjunto semelhante ao número. "É representada pelo espaço... é uma multiplicidade de exterioridade, de simultaneidade, de justa posição, de ordem, de diferenciação quantitativa, de diferença de grau, uma multiplicidade numérica, descontinua e atualizada" (Deleuze, 1989, p. 30). A multiplicidade qualitativa, por sua vez, é interna, sucessiva e somente aparece na pura duração, porque é uma multiplicidade temporal e não espacial. Própria dos estados internos da consciência, que se sucedem fundindo-se e a cada nova fusão mudando por completo sua natureza. "Presente na duração pura; é uma multiplicidade interna, de sucessão, de fusão, de organização qualitativa ou de diferença de natureza, uma multiplicidade virtual e contínua, irredutível ao número" (Deleuze, p. 30). Portanto, na duração interna tudo se modifica o tempo todo porque o progresso dos estados psicológicos é dinâmico; se algo se solidifica é porque nos deixamos representar, ilusoriamente, a nós mesmos, como se existíssemos num tempo homogêneo e espacial. Nossa representação, de nossa duração psicológica como uma multiplicidade quantitativa e homogênea, se origina de uma invasão imprópria do espaço no âmbito da pura duração, como veremos.

\section{Na Origem do Problema: A Confusão entre Tempo e Espaço}

Na raiz do problema está a confusão que se faz entre tempo e espaço quando não se percebe que os estados psicológicos e toda vida psíquica são de natureza temporal 
e não espacial. A partir desta confusão, tem-se a representação de um eu superficial e de uma multiplicidade quantitativa dos estados da consciência porque se concebe a vida psíquica existindo num tempo espacial.

Os pressupostos do determinismo psicológico, enquanto ciência, foram levantados sobre uma base filosófica comum, onde encontramos como idéia central o conceito de tempo homogêneo. Este conceito surge da aplicação imprópria de noções como quantidade, extensão e espaço à concepção do tempo psíquico, deformando o tempo-qualidade vivido pelo eu, transformando-o no tempo-quantidade representado pelo espaço. Tal deformação, no fundo, ocorre porque se confunde a verdadeira duração da psique com sua representação simbólica, ou seja, substitui-se o tempo pelo espaço. Este tempo homogêneo pode ser definido como um misto de tempo e espaço. A duração homogênea não é a verdadeira duração, mas um conceito híbrido, formado por meio da representação espacial que introduz seus cortes descontínuos na sucessão interna, heterogênea e contínua da duração psicológica. Bergson explica como se processa esta confusão entre tempo e espaço:

"Mas familiarizados com esta última idéia (espaço), e obsessionados até por ela, introduzimo-la sem saber na nossa representação da sucessão pura; justapomos nossos estados da consciência de maneira a percepcioná-los simultaneamente, não já um no outro, mas um ao lado do outro; em resumo, projetamos o tempo no espaço, exprimimos a duração pela extensão, e a sucessão toma para nós a forma de uma linha contínua, ou de uma cadeia, cujas partes se tocam sem se penetrar." (Bergson, 1889/1988, p. 73)

O tempo-quantidade (ou duração homogênea) é apresentado como um meio homogêneo onde os fatos da consciência se alinham e se justapõem formando uma multiplicidade quantitativa e onde cada estado separadamente se sucede um após o outro, sendo assim, é uma representação absolutamente distinta da verdadeira duração. Quando definimos o tempo desta forma o que estamos definindo na realidade é o espaço e a verdadeira duração não tem a menor relação com o espaço. "Esta forma do tempo é somente uma representação da nossa intuição do tempo em termos de espaço" (Hude 1990, p. 136).

O tempo homogêneo tem sua origem numa "endosmose entre o interno e o externo" (Prado Jr., 1989, p. 99). A confusão é bilateral. De um lado, ocorre uma aparente temporalização do espaço, por meio da ilusão de que possa ocorrer uma sucessão num meio homogêneo; fato impossível porque qualquer sucessão somente ocorre no tempo e para a consciência. A ilusão da existência de sucessão num meio homogêneo surge porque inventamos um espaço invadido pelo tempo, sobre o qual podemos justapor quantidades, esquecendo do ato essencial do espírito que realiza esta justaposição. De outro lado, ocorre uma especialização do tempo interno invadido pelo modo de ser do que é externo, dando origem, assim, a duração homogênea. A duração interna representada como homogênea, surge exatamente desta troca entre a exterioridade e a interioridade. O que possibilita este movimento de endosmose, entre o tempo puro e o espaço puro, é a simultaneidade, que segundo Bergson: "se poderia definir como a intersecção do tempo e do espaço." (Bergson, 1889/1988, p. 78). Se não houvesse simultaneidade, entre o externo e o interno, a endosmose seria impossível. Somente porque um fenômeno exterior ocorre ao mesmo tempo em que o percebo no meu interior modificando os estados da minha consciência, é que ocorre uma troca ente o espaço exterior e a duração interior. Portanto, é a simultaneidade que possibilita a endosmose espaço-temporal que produz o tempo homogêneo. " $\mathrm{Na}$ medida em que o tempo aparece como multiplicidade numérica, medir a duração significa contar simultaneidades. Quando aplicamos este conceito de duração à vida psicológica, formamos um conjunto suscetível de decomposição e recomposição de elementos simultâneos. A simultaneidade é a noção-chave nesta endosmose entre tempo e espaço" (Leopoldo e Silva, 1994, p. 136).

Substituímos o espaço pelo tempo e definimos o tempo interior como um meio vazio e homogêneo preenchido por uma sucessão de fatos psicológicos, da mesma maneira que concebemos o espaço como um meio vazio e homogêneo preenchido por uma coexistência. Essa homogeneidade pode ser entendida como ausência de qualidade, assim, o tempo homogêneo é um tempo sem qualidade no qual os fatos da consciência com seus contornos definidos e exteriores uns aos outros se sucederiam. "A tese geral de Bergson é bem conhecida: nós projetamos sobre a duração verdadeira, infinitamente móvel, o espaço no qual nós vivemos visando a comodidade social" (Vieillard-Baron, 1991, p. 58).

Mas o tempo homogêneo não é o tempo real porque, segundo Bergson: "os fatos da consciência, ainda que sucessivos, penetram-se, e no mais simples deles pode refletir-se a alma inteira" (Bergson, 1889/1988, p. 71). Assim, Bergson vê o tempo real como heterogêneo e qualitativo. Se o tempo fosse homogêneo e sem qualidade seria espaço; se definirmos espaço como homogêneo tudo que é homogêneo é espaço, isto porque seria contraditória a existência de duas homogeneidades distintas. A confusão entre estes "dois tempos" ocorre porque movidos por interesses úteis à ação, 
espontaneamente substituímos o tempo verdadeiro da existência e da consciência pela ilusão do tempo da ciência e da vida cotidiana. Assim é que, introduzindo a idéia de espaço na pura duração que se chega à idéia de um tempo homogêneo e sem qualidade, usado pela ciência determinista e pela psicofísica que acabaram por tirar do tempo o essencial, isto é, a duração.

Bergson (1889/1988), como vimos, constrói sua crítica ao conceito de tempo homogêneo espacial a partir da percepção de que existem dois tipos distintos de multiplicidade, uma qualitativa e outra numérica, que levam respectivamente a duas concepções diferentes acerca da natureza do tempo: um heterogêneo e contínuo e outro homogêneo e divisível. O erro do determinismo psicológico, denunciado por Bergson, foi o de ter aplicado o conceito de tempo espacial à compreensão do modo de ser do psiquismo. Bergson demonstra que o tempo homogêneo é uma noção híbrida de tempo e de espaço que surge porque se concebe a duração como homogênea, concepção que no fundo não passa de uma representação simbólica e inexata da verdadeira realidade psíquica.

Para Bergson (1889/1988), há o tempo real: a duração. Tempo que é mudança essencial e contínua; tempo que passa incessantemente modificando tudo e que constitui a própria essência da realidade psíquica. Todavia, não é assim que percebemos a realidade; presos aos hábitos da inteligência visando a nossa ação no mundo, percebemos a realidade como estática e passível de ser fragmentadas em partes que facilitam nosso agir no mundo. Temos, assim, uma concepção espacial da realidade, que olha o mundo do ponto de vista da extensão. A esta visão espacial da realidade, escapa o tempo real, que flui incessantemente em seu contínuo movimento, porque pensa o tempo nos moldes do espaço e, assim, concebe um tempo ilusório: o tempo espacializado, originado da confusão que inadvertidamente se faz entre tempo e espaço ${ }^{3}$. E a consciência, imbuída de representações espaciais, olha para si mesma e não se reconhece como duração pura, enxerga estados que se sucedem sem se penetrarem, não vê o eu no seu conjunto inter-relacionado, esquece o passado num lugar escondido sem relação com o presente, torna as sensações e os sentimentos unidades estanques sem movimento, concebe a imobilidade como substrato da realidade.

Somente da confusão entre duas realidades distintas, tempo e espaço, é que surge a idéia de tempo homogêneo,

\footnotetext{
${ }^{3}$ Bergson trata dessa ilusão em seu Ensaio sobre os Dados Imediatos da
} Consciência (1889/1988, a partir da p. 57). representação simbólica da verdadeira duração, sobre a qual se construiu a psicofísica e outras formas de representação do mundo que carregaram consigo este equívoco primordial. Para evitar equívocos, é necessário distinguir o tempo do espaço e pensar a vida psíquica como essencialmente temporal. Para tanto, Bergson esclarece que:

"Há um espaço sem duração, mas onde fenômenos aparecem e desaparecem simultaneamente com os nossos estados da consciência. Há uma duração real, cujos momentos heterogêneos se interpenetram podendo cada momento aproximar-se de um estado do mundo exterior que é dele contemporâneo e separar outros momentos por efeito dessa aproximação. Da comparação destas duas realidades nasce uma representação simbólica da duração, tirada do espaço. A duração toma assim a forma ilusória de um meio homogêneo" (Bergson, 1889/1988, p. 78).

Assim, não podemos reduzir a noção de tempo à noção de espaço porque são realidades distintas. Logo, é necessária a depuração do misto entre tempo e espaço, da qual surgirá, de um lado, o puro espaço e, de outro lado, a pura duração ${ }^{4}$. Esclarecer essa confusão é um dos principais objetivos do Ensaio sobre os Dados Imediatos da Consciência (Bergson, 1889/1988); trata-se, pois, de separar duas concepções diferentes de tempo, de um lado, o tempo-espacial utilizado pela ciência, de outro lado, o tempo interior, no qual vive e dura o eu. "Em verdade, o tempo da ciência é assim o tempo da linguagem, a expressão de uma espécie de 'senso comum' cuja vocação natural e de pensar visando a agir. O tempo da existência é, ao contrário, esse da duração interiormente vivida e, de fato, interiormente percebida" (Gouhier, 1989, p. 42). Portanto, devemos separar duas realidades distintas: primeiro, um espaço sem duração onde somente existe o presente absoluto e, segundo, uma duração pura onde encontramos o tempo real passando contínuo e heterogêneo, no qual ocorrem os fenômenos psíquicos.

Bergson (1889/1988) busca construir uma metafísica que não ignora a realidade de fato. Compreende que o primeiro acesso a essa realidade é a vida interior, constituída por nossa psique; assim, volta seu olhar a esse acesso privilegiado, buscando compreender sua natureza, antes de buscar investigar a realidade tida como exterior. Descobre que essa vida interior é de natureza temporal: o tempo, enquanto duração, é a essência da vida psíquica.

\footnotetext{
4 Distinção que permanecerá até a formulação da duração como sendo a própria substância das coisas, em A Evolução Criadora (1907), que tornará evidente o caráter metodológico desta distinção. Por hora, aceitemos esta distinção, que nos ajudará em muito a compreender a noção de tempo homogêneo.
} 
Todavia, não é assim que, no geral, a psicologia de seu tempo a entendeu; marcada pelo determinismo psicofísico, acabou por não reconhecer a verdadeira natureza psíquica, ao confundi-la com o físico, entendendo-a como sendo de natureza espacial. A contribuição de Bergson está em mostrar que é necessário pensar os pressupostos filosóficos da psicologia e, assim, manter um diálogo entre filosofia e psicologia, disciplinas que por muito tempo caminharam juntas.

\section{Referências}

Bergson, H. (1988). Ensaio sobre os dados imediatos da consciência (J. S. Gama, Trad.). Lisboa: Edições 70. (Original publicado em 1889)
Bergson, H. (1984). Cartas, conferências e outros escritos (F. L. Silva, Trad.). São Paulo, SP: Abril Cultural, Coleção Os Pensadores. (Original publicado em 1903)

Bergson, H. (1964). A evolução criadora (A. C. Monteiro, Trad.). Rio de Janeiro, RJ: Editora Delta. (Original publicado em 1907)

Deleuze, G. (1989). Le bergsonisme. Paris: P.U.F.

Gouhier, H. (1989). Bergson dans l'histoire de la pensée occidentale. Paris: J. Vrin. Hude, H. (1990). Bergson. Paris: Éditions Universitaires.

Leopoldo e Silva, F. (1994). Bergson: Intuição e discurso filosófico. São Paulo, SP: Loyola.

Prado Jr., B. (1989). Presença e campo transcendental: Consciência e negatividade na filosofia de Bergson. São Paulo, SP: Edusp.

Trotignon, P. (1967). L'idée de vie chez Bergson. Paris: P.U.F

Vieillard-Baron, J. L. (1991). Bergson. Paris: P.U.F.

Recebido: 26/12/2000

Revisado: 02/05/2001

Aceite Final: 18/06/2001

Sobre a autora

Regina Rossetti é Filósofa, Pesquisadora de Pós-Doutorado da Fapesp, Doutora em Filosofia pela Universidade de São Paulo. 